\title{
Black cloud with a silver lining
}

The soot produced by incomplete burning of carbon is a more potent warming agent than previously thought, according to a four-year international study (J. Geophys. Res. http:// dx.doi.org/10.1002/jgrd.50171; 2013). The result adds impetus to programmes that aim to quickly reduce global warming and also improve public health by cutting black carbon emissions.

Soot warms the world by 1.1 watts per square metre, concludes a team of 31 scientists working with the International Global Atmospheric Chemistry Project, using the latest data and modelling. This puts black carbon second only to carbon dioxide as a global warming agent. The new figure is higher than most (but not all) previous estimates of soot's warming power: it is nearly twice the number agreed on by the Intergovernmental Panel on Climate Change in 2007.

Black carbon lasts only days or weeks in the atmosphere - carbon dioxide, by comparison, hangs around for centuries, and methane stays for a decade or so. This makes soot an ideal target for quick corrections to the planet's warming trend. Efforts are already in place to cut down on black carbon to reduce both climate warming and respiratory disease. The Climate and

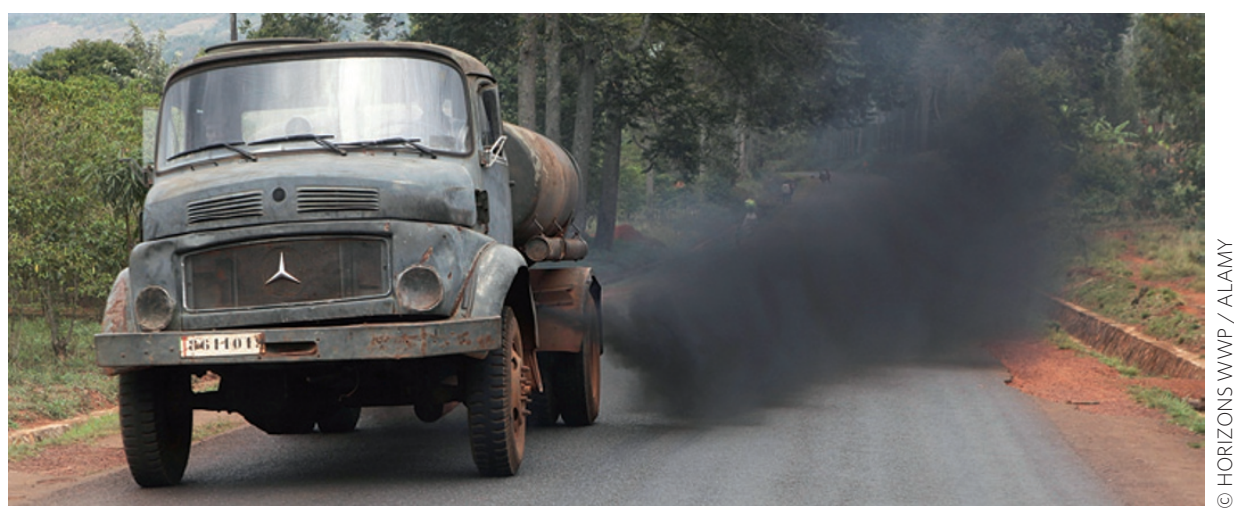

Clean Air Coalition to Reduce Short-Lived Climate Pollutants, for example, which was formed in February 2012, aims to reduce sooty emissions from diesel trucks, brick production and the oil and gas industries. Other initiatives are working to replace the dirty coal or biomass cooking stoves used in many homes in the developing world.

Assessing the warming impact of soot is extremely complex. Black particles absorb sunlight and warm the air, and they darken ice and snow, reducing the amount of heat reflected back into space. They also have smaller, indirect effects: they alter cloud reflectivity and formation, heating or cooling the planet depending on altitude and other factors. The new work is a comprehensive assessment that attempts to account for all of this.

An added complication is that some black carbon sources - such as forest fires - simultaneously produce other pollutants that have a counteracting cooling effect. The authors caution that steps to cut emissions for climate reasons should target sources such as diesel engines that clearly have a short-term net heating effect.

Nicola Jones is a freelance journalist based in Pemberton, British Columbia, Canada.

\section{The journalist's take}

Journalists sometimes suffer from 'climate change fatigue' - a sense of lethargy and depression arising from a constant barrage of similar-sounding stories about the terrible and inevitable impacts of global warming. Although the science progresses, the general conclusions remain the same rising temperatures, melting ice and more weather extremes - and so sound like old news. Mitigation efforts can seem hopeless or painful. Governmental efforts to get greenhouse gas emissions under control fail time and time again. Even if emissions were halted tomorrow, we are told, warming will still continue for a century. Emission cuts involve energy-restricting lifestyle changes that require abandonment of many of the traditional markers of success in the western world, from large homes and cars to holidays abroad.

Stories about black carbon offer a refreshing change: the culprit is dirty and bad for health as well as for the climate. Cutting emissions can be achieved by upgrading old technologies in the developing world, without painful lifestyle changes. It's a win-win situation. And the proposed fix for global warming (even if for only a temporary patch) is mercifully quick and effective.

These factors help to explain why black carbon studies get press coverage - repeatedly. Stories about soot ranking second to carbon dioxide as a warming agent go back to at least 2001, when a study was published by one of the co-authors of the latest report (Nature 409, 695-697; 2001). A Review in this journal (Nature Geosci. 1, 221-227; 2008) put a thenanomalously high figure of $0.9 \mathrm{~W} \mathrm{~m}^{-2}$ on just the direct warming power of black carbon interestingly, the new work comes up with an almost identical figure of $0.88 \mathrm{~W} \mathrm{~m}^{-2}$. That Review received a lot of press. So too did a paper, again led by one of the coauthors of the latest report, arguing that cutting black carbon and methane emissions could reduce global warming by $0.5^{\circ} \mathrm{C}$ by
2050, providing a good chance of keeping warming below $2{ }^{\circ} \mathrm{C}$ (Science 335, 183-189; 2012). At that time, New York Times journalist John Tierney put his finger nicely on the win-win aspect of cutting short-lived pollutants: "No matter what people think about global warming, there aren't a lot of fans of dirty snow [...] and diseased lungs" (http://go.nature.com/Ccu98D).

Journalists had another incentive to cover the latest report: it was a large study led by an international project group. In a field such as climate change, where uncertainties can be large and debates fierce, journalists are pleased when they can lean on the authority of a report that boasts strength in numbers.

It is often said that journalists are drawn to bad news - and that's true. But the same dire news told over and over again leaves a sour taste in everyone's mouths. Journalists, too, crave practical solutions to big problems. Black carbon stories help to provide that. 